OLGU SUNUMU / CASE REPORT

\title{
Frontal kavernoma cerrahisi sonrası fizyoterapi ve rehabilitasyon sonuçları
}

\author{
Physiotherapy and rehabilitation outcomes after frontal cavernoma surgery \\ Ayşe Ünal ${ }^{1}$, Güzin Kara ${ }^{1}$, Gülsüm Tikaç ${ }^{1}$, Filiz Altuğ ${ }^{1}$ \\ 1Pamukkale Üniversitesi Fizik Tedavi ve Rehabilitasyon Yüksekokulu, Denizli, Turkey
}

\begin{abstract}
The aim of our study was to determine the functional results of the patient under the physiotherapy and rehabilitation program after frontal cavernoma surgery. A 23-year-old patient who was operated due to cortically placed cavernoma in left frontal lobe has been presented in this case report. The patient was evaluated at 5th day and three month after surgery. In this period, physiotherapy program including grabbing exercises in order to improve hand skills, walking exercises, climbing up-down stairs and balance exercises was applied and the patient was discharged from the hospital advice home exercises. After physiotherapy program, patient has significantly improved. Physiotherapy and rehabilitation program after frontal cavernoma surgery can be effective in functional recovery of the patients.
\end{abstract}

Key words: Physiotherapy, frontal cavernoma, neurosurgery

\section{GİRİŞ}

Kavernomalar merkezi sinir sisteminin vasküler malformasyonları olarak siniflandirilan ve nadir görülen benign lezyonlardır ${ }^{1}$. $\mathrm{Bu}$ patolojiler literatürde kavernöz anjiom veya kavernom olarak da adlandırılır. Kavernöz hemanjiomlar büyük sinüzoidal vasküler boşlukların birleşmesiyle oluşan, içerisinde musküler ve nöral dokuya ait yapılar izlenmeyen yapılardır ${ }^{2}$. Kavernöz malformasyonlar genel populasyonda $\% 0.4-0.5$ oraninda görülmektedir ${ }^{3}$. Kavernomaların $\% 75$ 'i subkortikal ve supratentoriyal yerleşimlidir ve genellikle frontal ve temporal lobda görülmektedir. Genellikle nöbet, hemoraji ve nörolojik semptomlarla birlikte görülür ${ }^{4}$.

\section{Öz}

Çalışmamız frontal kavernom cerrahisi sonrasında fizyoterapi ve rehabilitasyon programına alınan hastanın fonksiyonel sonuçlarını incelemek amacıyla yapılmışıtı. $\mathrm{Bu}$ çalısmada sol frontal lobda kortikal yerleşimli kavernom sebebiyle cerrahi geçiren ve ardından fizyoterapi programına alınan 23 yaşındaki bir olgu sunulmuştur. Olgu cerrahi sonrasında beşincigünde ve üçüncü ayda değerlendirilmiștir. $\mathrm{Bu}$ süreçte el becerilerini arttırmaya yönelik olarak kavrama eğitimi, yürüme eğitimi, merdiven çıkma-inme ve denge egzersizlerini içeren fizyoterapi programı uygulanmış ve ev programı verilerek taburcu edilmiştir. Fizyoterapi programından sonra hasta önemli gelişme kaydetmiştir. Frontal kavernoma cerrahisi sonrası hastaya uygulanacak fizyoterapi ve rehabilitasyon programının hastanın fonksiyonel geri dönüşüne katkıda bulunacağ düşünülmektedir.

Anahtar kelimeler: Fizyoterapi, frontal kavernom, nöroşirürji

Problemlerin çoğu serebral cerrahi sonrası erken ve geç dönemde ortaya çıkmaktadır. Hemoraji, nöbetler, motor fonksiyon hasarları, görme bozuklukları, motor ve duyusal afazi bunlardan bazılarıdır ${ }^{1}$. Kavernomaların lokalizasyonuna göre cerrahi öncesi ve özellikle cerrahi sonrası fizyoterapi ve rehabilitasyon programları hastanın günlük yaşam aktivitelerindeki fonksiyonelliğini ve yaşam kalitesini arttırmak açısından önem taşımaktadır. Literatürde de çok nadir olarak karșılașılan kavernomalı hastaların fizyoterapi ve rehabilitasyonları bu denli önem taşımasina rağmen, bu alanda yapılan çalışmalar oldukça kısıtlıdır.

Çalışmamız frontal kavernom cerrahisi sonrasında fizyoterapi ve rehabilitasyon programına alınan 
hastanın fonksiyonel sonuçlarını incelemek amacıyla yapılmıştır.

\section{OLGU}

Bu çalışmada Pamukkale Üniversitesi Hastanesi Beyin Cerrahisi Servisi'nde sol frontal lobda kortikal yerleşimli kavernom sebebiyle cerrahi geçiren ve ardından fizyoterapi programına alınan 23 yaşındaki kadın bir olgu sunulmuştur. Olgu yazılı ve sözlü olarak bilgilendirilmiş ve onam alınmıştır.

Olgu cerrahi sonrasında beşinci günde ve cerrahiden üç ay sonra Hodkinson Mental Test, Jebsen El Fonksiyon Testi, Zamanlı Kalk-Yürü Testi, $10 \mathrm{~m}$. Yürüme Testi, SF 36 Yaşam Kalitesi Ölçeği, Berg Denge Skalası, Beck Depresyon Ölçeği, Barthel İndeksi ile değerlendirilmiştir.

Hodkinson Mental Test toplam 10 sorudan oluşmaktadır. Doğru cevaplandırılan her soru bir puan olarak hesaplanmaktadır. 8-10 puan doğru cevap kognitif fonksiyon bozukluğu olmadığını, 6-7 puan doğru cevap hafif düzeyde fonksiyon bozukluğu olduğunu, beș puan ve altı doğru cevap ise ileri düzey kognitif bozukluğu gösterir ${ }^{5}$.

Jebsen El Fonksiyon Testi fonksiyonel el kullanımını değerlendirmek için pratikte sıklıkla kullanılan, ilk objektif ve standardize testlerden birisidir. Günlük yaşamda yapılan işlerde harcanan ortalama zamanı saniye(sn) cinsinden ölçen bir testtir. Bu teste göre bireylerde beş sayfa çevirme, altı küçük objeyi (iki para, iki ataç, iki gazoz kapağı) masa üzerinden alıp kutuya koyma, dört küpü üst üste yerleştirme, beş baklanın tabaktan kaşıkla alınıp başka bir kaba bırakma için geçen toplam süre her iki el için kaydedilir. Testin bir alt parametresi olan yazı yazma hız1, 20 kelimeden oluşan bir cümleyi yazma süresine bakılarak ayrıca değerlendirilir ${ }^{6}$.

Zamanlı Kalk-Yürü Testi klinikte kullanımı basit, gözlemciler arası ve test-tekrar test güvenilirliği yüksek bir testtir. Kişinin oturduğu sandalyeden ellerini kullanmadan kalkması ve üç metre normal yürüme hızında yürüdükten sonra dönüp sandalyeye geri yürüyerek oturması istenir. Görev tamamlanıncaya kadar geçen süre sn cinsinden ölçülür. Kesme değeri 13.5 sn'dir ve test sonucunun bu değerin altında olması beklenir ${ }^{7}$. $10 \mathrm{~m}$. Yürüme Testi için $30 \mathrm{~m}$.lik koridorda 10 m'lik yürüme alanı bant ile işaretlenir. Kişinin ayak başparmakları başlangıç çizgisinin hemen arkasındadır. Süre başlatıldığında kișiden $10 \mathrm{~m}$ mesafeyi mümkün olduğunca hızlı yürünmesi istenir. Üç sefer tekrar edilir ve ortalama alınır. Berg Denge Skalası, 14 maddeden oluşur ve her bir bölüm 0(kötü) ile 4(en iyi) arasında derecelendirilerek, oturmadan ayağa kalkma, ayaklar bitișik olarak ayakta durma, tandem pozisyonunda ayakta durma, tek bacak üzerinde dengede kalma gibi pozisyonlar sırasındaki bağımlılık ve/veya bağımsılılı düzeyini ve kişinin pozisyon değişikliği yapabilmesini ölçer. Alınan en yüksek puan, en iyi dengeyi göstermektedir. 0-20 puan düşme için yüksek riski, 21-40 puan orta riski ve 4164 puan düşük riski göstermektedir ${ }^{8}$.

SF 36 Yaşam Kalitesi Ölçeği, genel sağlık kavramlarını içerir ve hem fiziksel hem de mental sağlığ1 değerlendirir. 14 yaş ve daha büyüklerin, kendi kendilerine veya bu konuda bilgilendirilmiş bir bireyin eşliğinde uygulayabilecekleri şekilde hazırlanmıştır. Türkçe geçerlilik ve güvenilirliği saptanmış ve kronik fiziksel hastalıklarda kullanılabileceği belirtilmiştir ${ }^{9}$.

Beck tarafindan 1961de geliştirilen ve geçerlik ve güvenirlik çalışmaları Teğin(1980), Hisli(1988) tarafından yapılan Beck Depresyon Ölçeği ise karamsarlık, başarısızlık duygusu, doyum almama, suçluluk duyguları, huzursuzluk, yorgunluk, iștah azalması, kararsızlık, uyku bozukluğu, sosyal çekilme gibi depresif belirtilere ilişkin 21 maddeden oluşmaktadır. Her madde depresyona özgü bir davranışı belirleyen dört dereceli kendini değerlendirme ifadesini içermektedir ${ }^{10}$.

Barthel İndeksi, beslenme, yıkanma, öz bakımını yapabilme, giyinme, dişkılama kontrolü, idrar kontrolü, tuvalete gitme, yataktan tekerlekli sandalyeye geçebilme yetisi, yürüme ya da tekerlekli sandalyeye bağımlı olma gibi hareketlilik durumu ve merdiven çıkma gibi işlevleri derecelendiren toplam 10 maddeden oluşmaktadır. Alınabilecek puanın 0100 arası olduğu bu ölçekte, skorun yüksekliği hastanın o derece diğer insanlardan bağımsız olduğu, kendi işini yürütebildiği anlamına gelir ${ }^{11}$.

$\mathrm{Bu}$ süreçte hastaya uygulanan fizyoterapi ve rehabilitasyon programinda el becerilerini arttırmaya yönelik olarak kavrama eğitimi (farklı büyüklükte ve şekillerde, farklı dokusu olan cisimleri kavrama), yürüme eğitimi (farklı zeminlerde yürüme, engelli yürüme, 8 çizerek yürüme), merdiven çıkma-inme ve denge egzersizleri verilmiştir. Haftada 5 gün, günde bir saat olmak üzere 15 seans fizyoterapi eğitimine devam edilmiştir. Aynı egzersizler ev programı olarak hastaya ve yakınlarına öğretilerek taburcu 
edilmiştir. Üç ayın sonunda tekrar kontrole çağrılarak tüm değerlendirmeler tekrar edilmiştir.

Jebsen El Fonksiyon Testi'nin bütün alt parametrelerine göre, hastanın el fonksiyonlarında gelişme olduğu, testleri daha kısa sürede tamamladığ1 görülmüștür (Tablo 1). Hastamız Zamanlı KalkYürü Testi ve $10 \mathrm{~m}$. Yürüme Testi'ni daha kısa sürede tamamlayıp, Berg Denge Skalasi'nda postoperatif beşinci günde 51 puan alırken, 3. ayda 56 puan alarak denge fonksiyonlarında iyileșme kaydedilmiştir (Tablo 2). Hastanın Hodkinson Mental Test ve Beck Depresyon Ölçeği'nden aldığ puan değişmezken, Barthel İndeksi ve SF 36 Yaşam Kalitesi Ölçeği sonuçlarında gelişmeler kaydedilmiştir (Tablo 3).

Tablo 1. Jebsen El Fonksiyon testi sonuçları

\begin{tabular}{|l|c|c|}
\hline Jebson El Fonksiyon Testi (sn) & Post op. 5. Gün & Post op. 3. Ay \\
\hline 5 sayfa çevirme & 8.35 & 7.32 \\
\hline 20 kelime yazma & 91.60 & 54.80 \\
\hline $\begin{array}{l}2 \text { para, 2 ataç, 2 gazoz kapağını } \\
\text { masadan alıp bardağa koyma }\end{array}$ & 7.57 & 7.31 \\
\hline 4 tane dama taşını üst üste koyma & 6.93 & 6.42 \\
\hline Yemek yeme & 15.10 & 12.42 \\
\hline $\begin{array}{l}5 \text { tane boş konserve kutusunu } \\
\text { kavrayıp birakma }\end{array}$ & 8.72 & 5.44 \\
\hline $\begin{array}{l}5 \text { tane dolu konserve kutusunu } \\
\text { kavrayıp birakma }\end{array}$ & 8.75 & 5.60 \\
\hline
\end{tabular}

Tablo 2. Dinamik denge testleri sonuçları

\begin{tabular}{|l|c|c|}
\hline Denge Testleri & Post op. 5. Gün & Post op. 3. Ay \\
\hline Zamanlı Kalk-Yürü Testi (sn) & 11.48 & 10.24 \\
\hline 10 m. Yürüme Testi (sn) & 11.87 & 9.90 \\
\hline Berg Denge Skalas1 Puan1 & $51 / 56$ & $56 / 56$ \\
\hline
\end{tabular}

Tablo 3. Kognitif durum, günlük yaşam aktiviteleri, duygusal durum ve yaşam kalitesi ölçeği değerlendirme sonuçları

\begin{tabular}{|l|c|c|}
\hline & Post op. 5. Gün & Post op. 3. Ay \\
\hline Hodkinson Mental Test & 9 & 9 \\
\hline Barthel İndeksi & 85 & 60 \\
\hline Beck Depresyon Ölçeği & 6 & 60 \\
\hline SF 36 Yaşam Kalitesi Ölçeği & & 6 \\
\hline Fiziksel Fonksiyon & 65 & 25 \\
\hline Fiziksel Durumun Kısıtladı̆̆1 Roller & 0 & 0 \\
\hline Ruhsal Durumun Kısıtladığ1 Roller & 0 & 60 \\
\hline Enerji & 70 & 84 \\
\hline Ruhsal İyilik Hali & 80 & 50 \\
\hline Sosyal Fonksiyon & 50 & 22.5 \\
\hline Ă̆r1 & 60 & 60 \\
\hline Genel Sağlık & 80 & \\
\hline
\end{tabular}

\section{TARTIŞMA}

Çalıșmamızın sonucunda; cerrahi tedavi sonrasında el fonksiyonlarında, GYA katılımda, yürüme ve denge yeteneklerinde yetersizliği olan hastamızda fizyoterapi uygulamaları sonrasinda tüm fonksiyonlarda ilerlemeler kaydedilmiștir. Merkezi sinir sisteminin vasküler yapılarında nadir görülen malformasyonlardan olan kavernomalar, genellikle subkortikal ve supratentoriyal yerleşimli olup, s1k1l1kla frontal veya temporal loblarda görülebilmektedir ${ }^{4}$. Kavernomaların tedavisinde lokalizasyonuna ve semptomlarına göre gerekli görüldüğ̈̈ takdirde öncelikle cerrahi tedavi tercih edilir ${ }^{12}$. Cerrahi öncesi ve özellikle cerrahi sonrasi fizyoterapi ve rehabilitasyon programları hastanın 
günlük yaşam aktivitelerindeki fonksiyonelliğini, mobilitelerini ve yaşam kalitesini arttırmak açısından önem taşımaktadır ${ }^{13}$. Literatürde bilateral çalışma, modifiye zorunlu hareket terapisi, elektrik stimülasyonu, tekrarlı görev eğitimi gibi farklı yöntemlerle yapılan kavrama-bırakma eğitimlerinin el fonksiyonlarını geliştirdiği gösterilmiştir ${ }^{14}$. Çalışmamızda da fizyoterapi ve rehabilitasyon programı gören hastamızın Jebsen El Fonksiyon Testi'nin bütün alt parametrelerine göre, hastanın el fonksiyonlarında gelişme olduğu görülmüştür.

Fizyoterapi ve rehabilitasyon programı sonras1 el fonksiyonlarında gelişmeyi gösteren çalışmaların yanı sıra, dinamik denge ve yürüme parametrelerinde de gelişmelerin olduğunu gösteren çalışmalarla karşılaşılmaktadır ${ }^{15}$. Bizim çalışmamızda da hastamızın Zamanlı Kalk-Yürü Testi, 10 m. Yürüme Testi ve Berg Denge Skalası sonuçlarında fizyoterapi programı sonrasında gelişmeler kaydedilmiştir.

Geçirilen cerrahi ve serebral etkilenim sonrasında bu popülasyondaki hastaların kognitif ve duygusal durumlarının etkilenebildiği bilinmektedir ${ }^{16}$. Bu amaçla hastanın tedavi öncesi ve sonrası sonuçları incelendiğinde, Hodkinson Mental Test ve Beck Depresyon Ölçeği'nden aldığı puanların değişmediği görülmüştür. Frontal lob etkilenimi sebebiyle görülen motor, kognitif, duygusal semptomları bu hasta grubunun günlük yaşam aktivitelerindeki bağımsılıklarını ve yaşam kalitelerini de olumsuz etkileyebilmektedir ${ }^{17}$. Fizyoterapi programı ile günlük yaşam aktivitelerine katılımın artarak hastanın daha bağımsız bir yaşam sürmesi ve dolayısıyla yaşam kalitesinin yükselmesi beklenir. Bizim hastamızda da fizyoterapi programı sonrasında GYA katılımını değerlendiren Barthel İndeksi ve SF-36 Yaşam Kalitesi Ölçeği sonuçlarında gelişme kaydedilmiştir.

Frontal kavernoma cerrahisi öncesi ve sonrasinda hastada görülen semptomlara göre hastanın maksimum potansiyelini tekrar kullanabilmesini sağlayacak fizyoterapi programının oluşturulması önem taşımaktadır. Literatürde de çok nadir karşılaşılan kavernomalı hastaların fizyoterapi ve rehabilitasyonları bu denli önem taşımasına rağmen, bu alanda yapılan çalışmalar oldukça kısıtlıdır. Çalışmamızın bu alanda literatüre bir katkı niteliği taşıyacağını umuyoruz. Bu sebeple bu alanda daha fazla hasta üzerindeki fizyoterapi sonuçlarını inceleyen daha fazla çalışma yapılması gerektiğini düşünmekteyiz.

\section{KAYNAKLAR}

1. Özbek CÇ, Ataizi ZS, Yayla E, Baloğlu M, Ak Saral D. Right sided cavernoma presenting with cross aphasia after surgery. Journal of Neurological Sciences(Turkish). 2011;28:278-83.

2. Kalkan E, Keskin F, Karataş Y, Kaya B, Güney AÖ. Supratentoryal ve infratentoryal yerleşimli multiple kavernom olgusu. Cumhuriyet Tip Dergisi. 2013;35:124-7.

3. Mao Y, Zhao Y, Zhou LF, Huang CX, Shou XF, Gong JL et al. A novel gene mutation (1292 deletion) in a Chinese family with cerebral cavernous malformations. Neurosurgery. 2005;56:1149-53.

4. Zotta D, Rienzo Di A, Scogna A, Ricci A, Ricci G, Galzio R J. Supratentorial cavernomas in eloquent brain areas: application of neuronavigation and functional MRI in operative planning. J Neurosurg Sci. 2005;49:13-19.

5. Çetin SY, Gökalan Kara İ, Kitiş A. Evde yaşayan yaşlılarda sosyal katılımı etkileyen faktörlerin incelenmesi. Ergoterapi ve Rehabilitasyon Dergisi. 2014;2:11-20

6. Yücel H., Bumin G. El fonksiyonundaki yaşa bağlı değişimin cinsiyete göre incelenmesi. Furat Üniversitesi Sağlık .Bilimleri Tip Dergisi. 2010:24:912.

7. Eyigör S. Düşmelere yaklaşım. Ege Tip Dergisi. 2012:51:43-51.

8. Soyuer F, Senol V, Elmalı F. Huzurevinde kalan 65 yaş ve üstündeki bireylerin, fiziksel aktivite, denge ve mobilite fonksiyonları. Van Tip Dergisi. 2012;19:11621.

9. Koçyiğit H, Aydemir Ö. Kısa Form-36'nın Türkçe versiyonunun güvenilirliği ve geçerliliği. İlaç ve Tedavi Dergisi. 1999;12:102-6.

10. Beck, A.T.,Ward, C. H., Mendelson, M., Mock, J., Erbaugh, J. An inventory for measuring depression. Arch Gen Psychiatry. 1961;4:561-71.

11. Tamam B, Taşdemir N, Tamam Y. İnme sonrası demans: sıklığ1 ve risk faktörleri. Türk Psikiyatri Derg. 2008;19:46-56

12. Karabulut Gül Ş, Mayadağlı A, Özșeker N, KOçak M, Oruç AF, Gedik D et al. Kavernom tedavisinde stereotaktik radyoterapi. Turkiye Klinikleri J Med Sci. 2014;34:29-32.

13. Soysal M, Kara B, Arda MN. Intrakranial cerrahi geçiren hastalarda fizyoterapi programının fonksiyonellik üzerine etkisinin incelenmesi. Türk Nöroșirürji Dergisi. 2011;21:281-82.

14. Langhorne P, Bernhardt J, Kwakkel G. Stroke rehabilitation. Lancet. 2011;377:1693-702.

15. Bowden MG, Embry AE, Gregory CM. Physical therapy adjuvants to promote optimization of walking recovery after stroke. Stroke Research and Treatment. 2011;2011: 601416. 
16. Campanella F, Shallice T, Ius T, Fabbro F, Skrap M. Impact of brain tumour location on emotion and personality: a voxel-based lesion-symptom mapping study on mentalization processes. Brain. 2014:253245 .
17. Kim K, Kim YM, Kim EK. Correlation between the activities of daily living of stroke patients in a community setting and their quality of life. J Phys Ther Sci. 2014;26:417-9. 